\title{
Engineered peptide macrocycles can inhibit matrix metalloproteinases with high selectivity
}

\author{
Khan Maola, ${ }^{[a, b]}$ Jonas Wilbs, ${ }^{[a, b]}$ Jeremy Touati, ${ }^{[a]}$ Michal Sabisz,${ }^{[a]}$ Xu-Dong Kong, ${ }^{[a]}$ Alice Baumann, ${ }^{[a]}$ Kaycie \\ Deyle $^{[\mathrm{a}]}$ and Christian Heinis* ${ }^{[\mathrm{a}]}$
}

\begin{abstract}
Matrix metalloproteinases (MMPs) are zinc-dependent endopeptidases at the intersection of health and disease due to their involvement in processes such as tissue repair and immunity as well as cancer and inflammation. Because of the high structural conservation in the catalytic domains and shallow substrate binding sites, selective, small-molecule inhibitors of MMPs have remained elusive. In a tourde-force peptide engineering approach combining phage display selections, rational design of enhanced zinc chelation, and D-amino acid screening, we succeeded in developing a first synthetic MMP-2 inhibitor that combines high potency $\left(K_{\mathrm{i}}=1.9 \pm 0.5 \mathrm{nM}\right)$, high target selectivity, and proteolytic stability, and thus fulfills all the required qualities for in cell culture and in vivo application. Our work suggests that selective MMP inhibition is achievable with peptide macrocycles and paves the way for developing specific inhibitors for application as chemical probes and potentially therapeutics.
\end{abstract}

Matrix metalloproteinases (MMPs) are a family of $>20$ zincdependent endopeptidases that play pivotal roles in physiological processes, such as morphogenesis, angiogenesis, tissue repair, and immunity, as well as in pathological conditions such as cancer, arthritis, and inflammation. While much progress has been made in the past few decades in understanding the roles of MMPs using powerful tools such as MMP knockout mice, ${ }^{[1]}$ proteomic approaches, ${ }^{[2,3]}$ and partially selective inhibitors, ${ }^{[4]}$ many important questions remain unanswered such as the exact contribution of individual MMP proteases to the different physiological and pathologic processes. ${ }^{[5]}$ A difficulty in the study of MMPs is the lack of selective inhibitors for this class of proteases. With hundreds attempts by both industry and academia at designing selective inhibitors, there is still no selective small molecule inhibitor for an MMP family protein excepting MMP-13. Highly selective MMP inhibitors would first provide an invaluable research tool, and depending on the MMP, potentially offer drug candidates. ${ }^{[6]}$

Peptides represent a promising underexplored modality for developing small, selective MMP inhibitors because they can interact with extended surfaces and thus bind selectively to protein targets with shallow binding pockets while maintaining molecular weights close to those of small molecules. The potential for generating peptide inhibitors with high affinities and target specificities was demonstrated by the MMP-2 inhibitor APP-IP, a decapeptide with the ISYGNDALMP sequence derived from the amyloid precursor protein (APP) that displays a high affinity $\left(I C_{50}\right.$ $=30 \mathrm{nM}$ ) and good selectivity for MMP-2. ${ }^{[7]}$ Unfortunately, the linear peptide has a low proteolytic stability in cultured cells $\left(\mathrm{t}_{1 / 2}=30\right.$ $\mathrm{min}),{ }^{[8]}$ preventing its use in cellular assays and in vivo. Genetic fusion of APP-IP to a tissue inhibitor of metalloproteinase (TIMP)

improved affinity and stability but also substantially increased the size $(23 \mathrm{kDa}),{ }^{[8]}$ hindering efficient diffusion into tissues and thus reducing its attractiveness for in vivo applications. For generating small and proteolytically stable MMP inhibitors, large libraries of disulfide-cyclized peptides were screened by phage display. These selections yielded MMP-2 and MMP-9 inhibitors, though with impractical binding affinities in the micromolar range. ${ }^{[9]}$

In this work, we addressed the long-standing challenge of developing selective synthetic inhibitors of MMPs by exploiting i) the power of phage display to screen large libraries, ii) a bicyclic peptide format demonstrated to have high resistance to proteases, and iii) a rational design to introduce a synthetic zinc-chelating group (Figure 1a). In our work, we chose MMP-2 as an example because it was reported to play key roles in many physiological processes as well as in diseases including in tumor growth and invasion. ${ }^{[6,10]}$

We prepared the bicyclic peptide phage display library shown in Figure $1 \mathrm{~b}$ as previously described ${ }^{[11]}$ and panned it against activated MMP-2 (Figure S1) immobilized on magnetic beads. DNA sequencing after the last selection round and comparison of the isolated peptide sequences revealed five different consensus groups and identified one peptide that was particularly strongly enriched (20 copies; peptide M21) and that was not similar to the other peptides (Figure 1b). The peptides of the five consensus

Figure 1. Peptide engineering approach and phage selection. (a) Iterative generation of diversity and identification of MMP-2 inhibitors with improved activity. (b) Phage selection of MMP-2 inhibitors indicating the library format ( $\mathrm{X}$ indicates random amino acids; the three cysteines are connected by the chemical linker TBMB). (c) Alanine scan of M21. The asterisks indicate that no inhibition was observed at the highest peptide concentration tested $(100 \mu \mathrm{M})$.

a

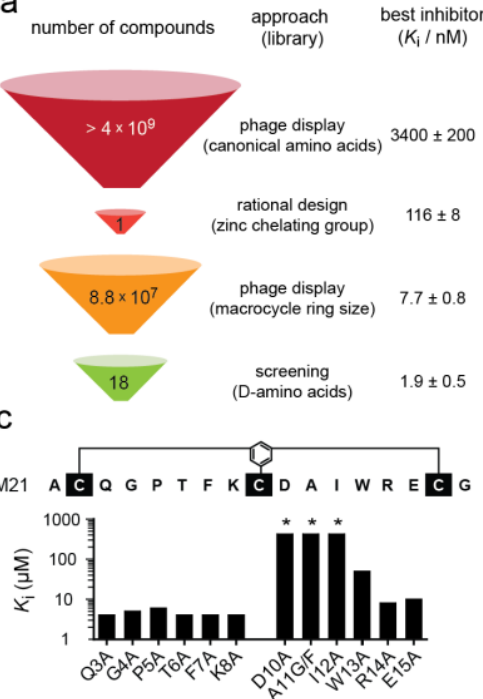

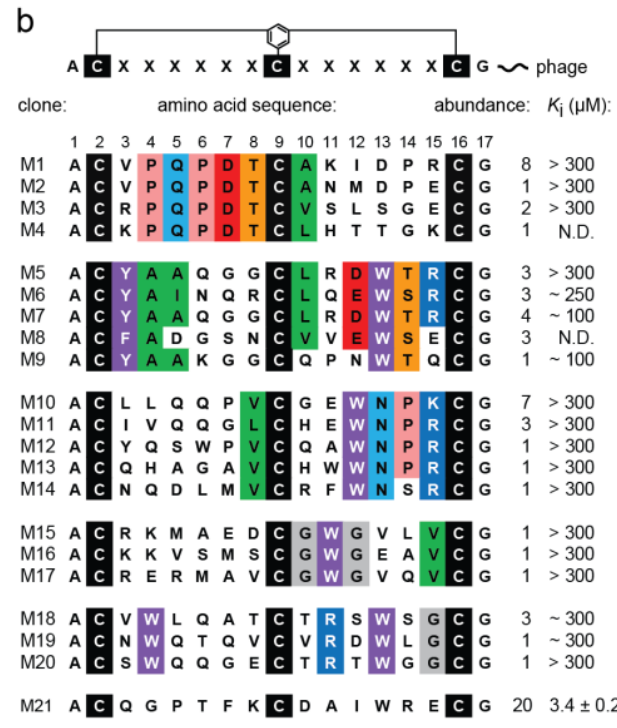



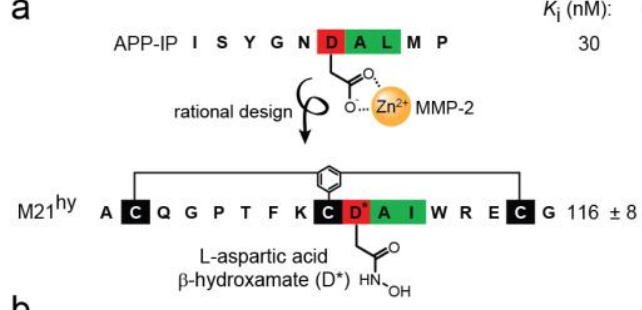

b

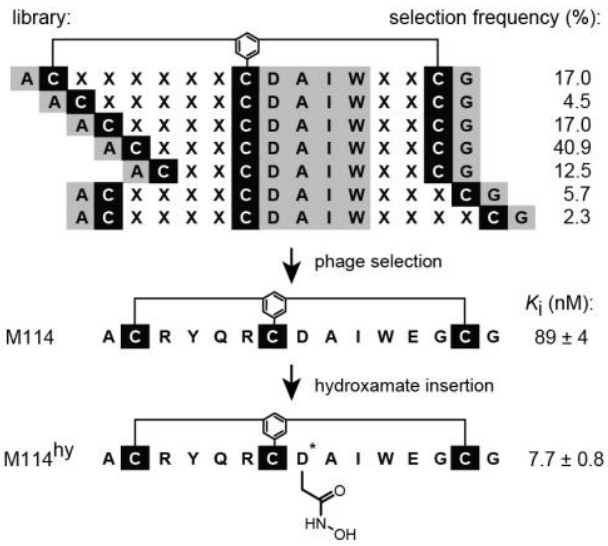
$\begin{array}{lccccc}\text { MMP-2 }^{\text {M }} & + & + & + & + & + \\ \text { M114 }_{(\mu \mathrm{M})} & - & 0.1 & 0.5 & 1 & - \\ \text { incubation } 37^{\circ} \mathrm{C} & 0 \mathrm{hr} & 1 \mathrm{hr} & 1 \mathrm{hr} & 1 \mathrm{hr} & 1 \mathrm{hr}\end{array}$ incubation $37^{\circ} \mathrm{C} \quad 0 \mathrm{hr} \quad 1 \mathrm{hr} \quad 1 \mathrm{hr} \quad 1 \mathrm{hr} \quad 1 \mathrm{hr}$

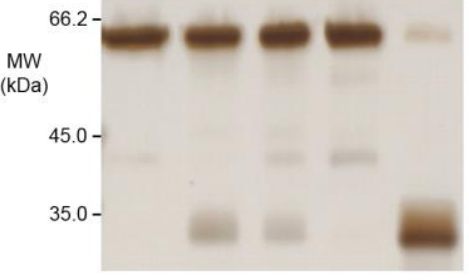

d

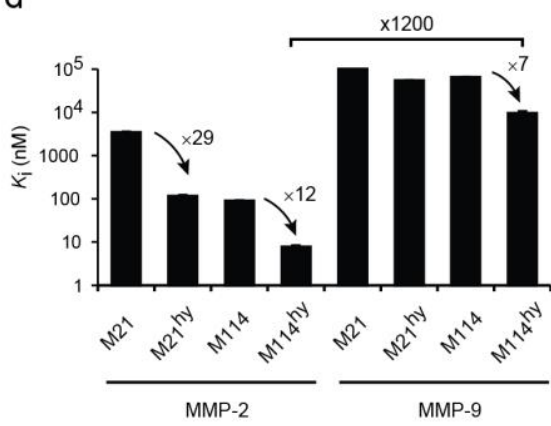

2 active site zinc ion, suggesting that Asp10 in the bicyclic peptide M21 forms the same interaction (Figure 2a). Given that hydroxamates bind more tightly to zinc ions than carboxyl groups, we reasoned that substitution of aspartate with L-aspartic acid $\beta$-hydroxamate (indicated as $\mathrm{D}^{*}$ in the figures) could potentially increase the binding strength of M21 by a large factor (Figure 2a). Towards this end, we synthesized M21 carrying a hydroxamate group on Asp10 (M21 $1^{\text {hy }}$. M21 $1^{\text {hy }}$ had a more than 30 -fold improved $K_{\mathrm{i}}$ for MMP-2 of $116 \pm 8 \mathrm{nM}$ $\left(\mathrm{M} 21 K_{\mathrm{i}}=3.4 \pm 0.2 \mu \mathrm{M}\right)$, indicating that our hypotheses that Asp is chelating the zinc and that M21 binds in a similar fashion to APP-IP are likely correct.

We further improved the affinity of the inhibitor by screening derivative phage peptide libraries based on M21 in which the number of amino acids per macrocyclic ring and the amino acid sequences were varied around the constant Asp-Ala-Ile-Trp core, as shown

Figure 2. Affinity improvement by rational design and in vitro selection. (a) Identification of zinc-chelating role of Asp based on homology to APP-IP and modification to hydroxamate. (b) Phage display libraries for optimization of bicyclic peptide ring sizes and the abundance of the formats after one round of phage selection. The sequences of the best inhibitor (M114) before and after insertion of the hydroxamate group (M114 ${ }^{\text {hy }}$ ) are shown. Other peptides isolated are shown in Figure S2 and S3. (c) Autodegradation of MMP-2 in presence of different concentrations of M114hy , analyzed by SDS-PAGE. (d) Inhibition of gelatinases MMP-2 and MMP-9 by M114 ${ }^{\text {hy }}$ and its precursors.

groups either did not inhibit MMP-2 or only blocked the protease activity at high micromolar concentrations, which we considered non-specific inhibition. In contrast, the abundant peptide M21 (ACQGPTFKCDAIWRECG) inhibited MMP-2 with a $K_{\mathrm{i}}$ of $3.4 \pm$ $0.2 \mu \mathrm{M}$. An alanine scan of M21 revealed that the first four amino acids of the C-terminal ring, Asp-Ala-Ile-Trp were most important for the binding (Figure 1c). Comparison of the M21 sequence with that of the above described MMP-2 inhibitor APP-IP ${ }^{[7]}$ showed similarities between the essential amino acids in both inhibitors (Figure 2a). ${ }^{[7,12]}$ Because the Xray structure of APP-IP a complexed to the MMP-2 catalytic domain was reported (PDB entry 3AYU), ${ }^{[13]}$ this could hint at the binding site and mode of M21.

APP-IP binds to the substratebinding cleft of MMP-2 in an outstretched, linear conformation, though in a direction opposite to that of the natural substrates in this cleft. ${ }^{[13]}$ The two oxygen atoms in the carboxyl group of Asp5 bidentately chelate to the MMP-

in Figure $2 b$ and described in detail in the Supporting Information. Peptide M114 containing the sequence Arg-Tyr-Gln-Arg in the first ring was most active, showing a $K_{\mathrm{i}}$ of $89 \pm 4 \mathrm{nM}$. Inserting the hydroxamate into M114 improved the affinity like for M21 and yielded the inhibitor M114 ${ }^{\text {hy }}$ with a $K_{\mathrm{i}}$ of $7.7 \pm 0.8 \mathrm{nM}$, which was 15-fold improved compared to the precursor M21 $1^{\text {hy }}$ (Figure 2b). The MMP-2 protein serves as a substrate for itself and can autocatalyze its own degradation into 42.5 and $32 \mathrm{kDa}$ cleavage products $^{[14]}$. To test whether M114 ${ }^{\text {hy }}$ inhibited both the cleavage of the short fluorogenic peptide substrate and protein substrates, we also tested the M114 ${ }^{\text {hy }}$ inhibition of MMP-2 self-degradation. Indeed, incubation of MMP-2 with M114 ${ }^{\text {hy }}$ also efficiently prevented auto-degradation of the protease (Figure 2c).

Figure 3. Improving the binding affinity using D-amino acids. (a) D-alanine scan of M114 ( $\left.K_{\mathrm{i}}=89 \pm 4 \mathrm{nM}\right)$. (b) Screening bicyclic peptide variants of M114 carrying diverse D-amino acids in position 13. (c) Combination of mutations of M205 (Arg6 $\rightarrow$ D Ala) and M215 (Gly13 $\rightarrow$ D-Phe) and modification of the Asp8 side chain to hydroxamate yields M219 $9^{\text {hy }}$. (d) Chemical structure of M219hy.

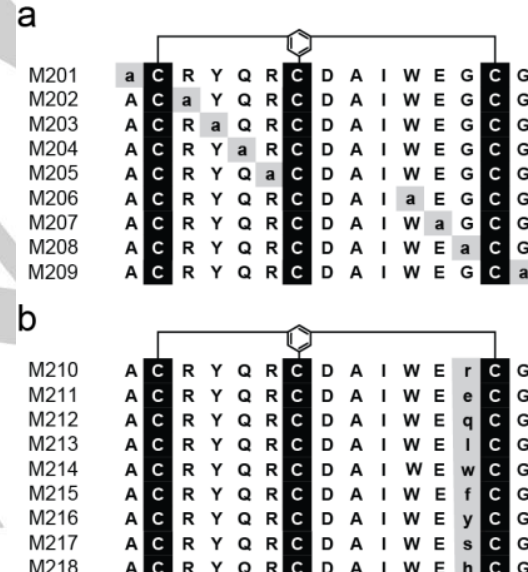

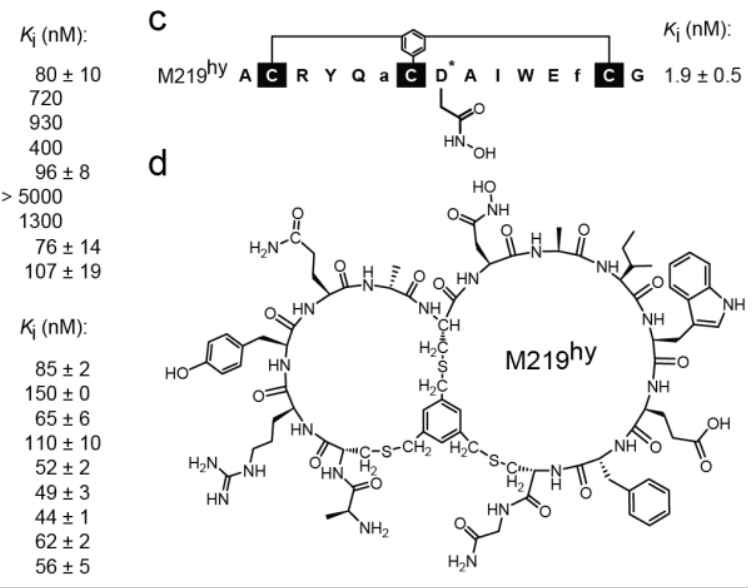


a

MMP-2

$\%$ identical aa

in catalytic in binding
domain site

\section{$K_{\mathrm{i}}$ of M219hy}

(nM)

$1.9 \pm 0.5$ $\begin{array}{lllllllllllll}4 & 73 & 81 & 83 & 84 & 85 & 86 & 87 & 120 & 121 & 124 & 129 & 130\end{array}$

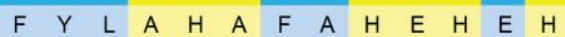
T S N A H A F Q H E H S H

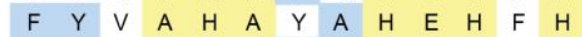

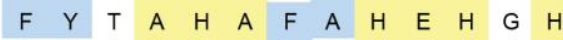
T S I A

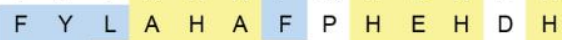
$\begin{array}{lllllllllllll}F & Y & S & A & H & A & Y & P & H & E & H & F & H\end{array}$ $M \quad H \quad I \quad A \quad H \quad A \quad F \quad G \quad H \quad E \quad H \quad G \quad H$ $\begin{array}{lllllllllllll}F & Y & L & A & H & A & F & P & H & E & H & D & H\end{array}$

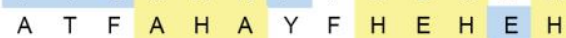
$Y \quad N \vee A \quad H \quad A \quad D \quad I \quad H \quad E \quad H \quad G \quad H$ F $Y$ T A H A F A H E H A H

C

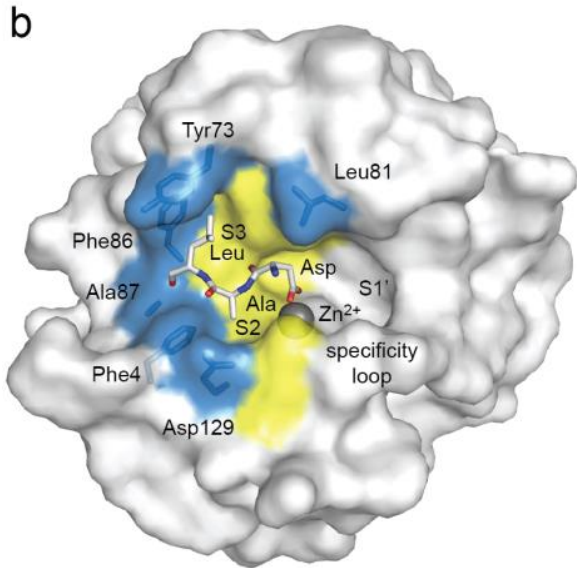

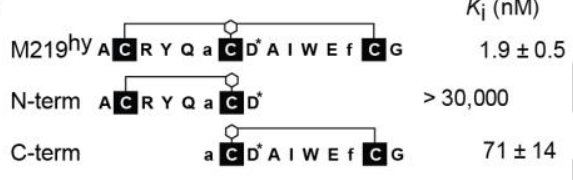

linear A A R Y Q a A D A I WE f A G

$2700 \pm 300$

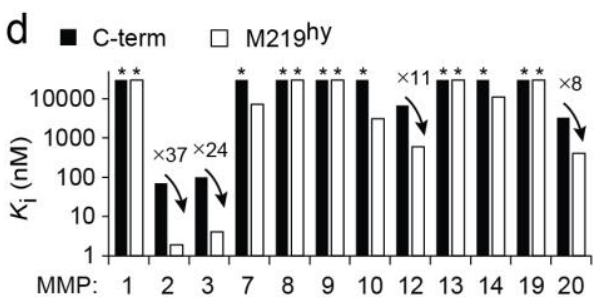

highest catalytic-domain sequence similarity to MMP-2, as assessed by a sequence comparison (BLOSUM62 Score; Table S2). The MMP catalytic domains are particularly similar in the non-prime substrate binding region to which M219 $19^{\text {hy }}$ likely binds based on the homology to APP-IP (Figs. 4a and 4b). A comparison of the 13 amino acids that form the approximately $1,000 \AA^{2}$ surface of this region (Figure $4 \mathrm{~b}$ ) showed that many of the MMPs differ in only two or three amino acids, underscoring the challenge of developing selective inhibitors to this site. Despite this challenge, M219 ${ }^{\text {hy }}$ was highly selective (>1,000-fold difference) for most MMPs and was largely selective over MMP-12 (300-fold) and MMP-20 (200-fold) (Figure $4 \mathrm{a}$ and Figure S4). Only one protease, MMP-3, was inhibited to a similar extent as MMP-2 $\left(K_{\mathrm{i}}=4.1 \pm 1.1\right.$ $n M)$. MMP-2 and MMP-3 do not share a common amino acid mutation or structural feature that is absent in all other MMPs and it is thus currently unclear why MMP-3 is the only other MMP that is efficiently inhibited by M219 ${ }^{\text {hy }}$. Dissecting the bicyclic peptide into individual rings or a linear analogue showed that the two ring systems alone and the bicyclic configuration were important for the affinity and selectivity (Figures $4 \mathrm{c}$ and $4 \mathrm{~d}$, and Figure S4), as described in detail in the Supporting Information.

To be applied as a research tool or as a therapeutic agent, inhibitors need to be sufficiently stable to sustain active target engagement in vitro or in vivo. We assessed the stability by incubating the inhibitors in human blood plasma for different time periods at $37^{\circ} \mathrm{C}$ and measuring the residual activity of the intact inhibitor and its metabolites in an MMP-2 inhibition assay. While APP-IP was inactivated in a relatively short time $\left(\mathrm{t}_{1 / 2}=33 \pm 5\right.$ minutes), the bicyclic inhibitors M114 hy and M219 hy had half-lives of $6.1 \pm 0.2$ and $8.3 \pm 0.9$ hours, respectively, and thus a more than 10-fold higher stability (Figure 5a). MS analysis of the degradation products revealed that M219 hy lost its activity due to hydrolysis of the hydroxamate which is a well-known event that occurs with small molecule hydroxamate inhibitors (Figure $5 \mathrm{~b}$ and Figure S5). ${ }^{[15,16]}$

Figure 5. Stability in human blood plasma. (a) The residual activities of APP-IP, M114 ${ }^{\text {hy }}$, and M219 ${ }^{\text {hy }}$ were quantified in an MMP-2 inhibition assay. (b) LC-MS analysis of peptides M219 hy and M219 (\% residual peptide) as shown in Figure S5b.

Now that we had shown selectivity for MMP-2 over a very similar family member, we desired a further improvement of the potency. To do this, we tapped into the sequence space of unnatural amino acids, which identified the beneficial mutations Arg6 $\rightarrow$ D-Ala and Gly13 $\rightarrow$ D-Phe (Figure 3a and $3 \mathrm{~b}$ ), as described in the Supporting Information. Combining the two mutations and re-inserting the hydroxamate group yielded M219 ${ }^{\text {hy }}$ with a 4-fold improved $K_{\mathrm{i}}(1.9 \pm 0.5 \mathrm{nM})$ compared to the M114 ${ }^{\text {hy }}$ precursor (Figure $3 \mathrm{c}$ and $3 \mathrm{~d}$ ).

We next profiled the specificity of M $219^{\text {hy }}$ by testing the inhibition of a panel of MMPs, including the nine with the
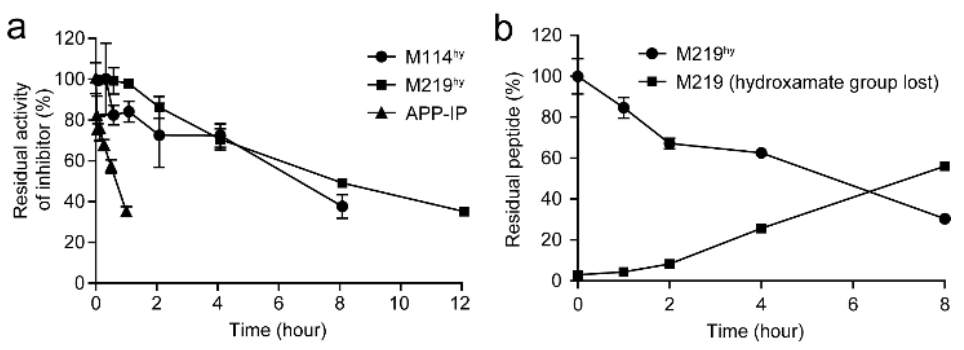
In summary, we show that the modality of peptide macrocycles is suited to generate MMP inhibitors with high selectivity. With its single-digit nanomolar binding affinity, high selectivity over all but one other MMPs, and good stability in cell culture and blood plasma, M219 hy provides a useful research tool for the investigation of the physiological and pathological roles of MMP-2 and MMP-3 and may even serve as a lead for future drug development. Additionally, the herein developed method for evolving MMP inhibitors with high selectivity could be directly applied to the acquisition of inhibitors for the other MMPs as well as ADAM/ADAMT subfamily proteases, and deliver the longdesired metalloproteinase inhibitors having high target selectivity.

\section{Acknowledgements}

Supported by the Swiss National Science Foundation (Grants 146794 , 157842 and NCCR Chemical Biology).

\section{Conflict of interest}

The authors declare no conflict of interest.

Keywords: matrix metalloproteinase $\bullet$ MMP-2 $\bullet$ peptides $\bullet$ phage display $\bullet$ selectivity

A. Page-McCaw, A. J. Ewald, Z. Werb, Nat. Rev. Mol. Cell Biol. 2007, 8, 221-233. C. J. Morrison, G. S. Butler, D. Rodríguez, C. M. Overall, Curr.
D. Rodríguez, C. J. Morrison, C. M. Overall, Biochim. Biophys. Acta - Mol. Cell Res. 2010, 1803, 39-54.

S. P. Gupta, Ed., Matrix Metalloproteinase Inhibitors, Springer Basel, Basel, 2012.

J. E. Meisel, M. Chang, Biochim. Biophys. Acta-Mol. Cell Res. 2017, 1864, 2001-2014.

R. E. Vandenbroucke, C. Libert, Nat. Rev. Drug Discov. 2014, 13, 904-927.

S. Higashi, K. Miyazaki, J. Biol. Chem. 2003, 278, 14020-14028. S. Higashi, T. Hirose, T. Takeuchi, K. Miyazaki, J. Biol. Chem. 2013, 288, 9066-9076.

E. Koivunen, W. Arap, H. Valtanen, A. Rainisalo, O. P. Medina, P. Heikkilä, C. Kantor, C. G. Gahmberg, T. Salo, Y. T. Konttinen, et al., Nat. Biotechnol. 1999, 17, 768-774.

C. M. Overall, O. Kleifeld, Nat. Rev. Cancer 2006, 6, 227-239.

1] C. Heinis, T. Rutherford, S. Freund, G. Winter, Nat. Chem. Biol. 2009, 5, 502-507.

S. Higashi, M. Oeda, K. Yamamoto, K. Miyazaki, J. Biol. Chem. 2008, 283, 35735-35744.

H] Hashimoto, T. Takeuchi, K. Komatsu, K. Miyazaki, M. Sato, S. Higashi, J. Biol. Chem. 2011, 286, 33236-33243. E. W. Howard, E. C. Bullen, M. J. Banda, J. Biol. Chem. 1991, 266, 13064-13069.

5] M. Flipo, J. Charton, A. Hocine, S. Dassonneville, B. Deprez, R. Deprez-Poulain, J. Med. Chem. 2009, 52, 6790-6802. R. K. Yadav, S. P. Gupta, P. K. Sharma, V. M. Patil, Curr. Med. Chem. 2011, 18, 1704-1722. Opin. Cell Biol. 2009, 21, 645-653. 


\section{Entry for the Table of Contents}

\section{COMMUNICATION}

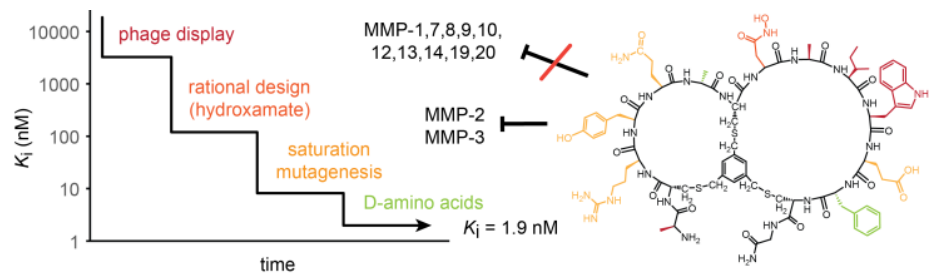

The selective inhibition of individual matrix metalloproteinase has been a great challenge due to high structural conservation in the catalytic domains and shallow substrate binding sites. Here we show that inhibitors with high selectivity for specific MMPs can be developed based on peptide macrocycles.
Khan Maola, ${ }^{[a, b]}$ Jonas Wilbs, ${ }^{[a, b]}$ Jeremy Touati, ${ }^{[a]}$ Michal Sabisz, ${ }^{[a]}$ Xu-Dong Kong, ${ }^{[a]}$ Alice Baumann, ${ }^{[a]}$ Kaycie Deyle ${ }^{[a]}$ and Christian Heinis $*[a]$

Page No. - Page No.

Peptide macrocycles promise to overcome the challenge of selectively inhibiting matrix metalloproteinases 


\section{Index}

\section{Supplementary Information}

Affinity maturation of M21 hy 2

Substitution of L- to D-amino acids 2

Importance of bicyclic format for affinity and selectivity 3

Stability and degradation pathways of MMP-2 inhibitors 3

Supplementary Materials and Methods

Experimental procedures $\quad 4$

Supplementary Tables

Supplementary Table 1: Selectivity of the bicyclic peptides for MMP-2 over MMP-9 12

Supplementary Table 2: Amino acid conservation in catalytic domain of MMPs 13

Supplementary Table 3: Specificity of M219hy, its rings, and the linear analogue 14

\section{Supplementary Figures}

Supplementary Figure 1: Expression, activation, and purification of MMP-2 15

Supplementary Figure 2: Saturation mutagenesis and isolated peptides 16

Supplementary Figure 3: Inhibitory activity of affinity-matured peptides 17

Supplementary Figure 4: Specificity of M219hy, its rings, and the linear analogue 18

Supplementary Figure 5: LC-MS analysis of APP-IP and M219 hy incubated in plasma 20 


\section{Supplementary Information}

\section{Affinity maturation of $\mathrm{M} 21^{\text {hy }}$}

Peptides of the form $\mathrm{ACX}_{\mathrm{m}} \mathrm{CDAIWX}_{\mathrm{n}} \mathrm{CG}\left(\mathrm{m}=3-6, \mathrm{n}=2\right.$ or $\mathrm{m}=4, \mathrm{n}=3-4$; library size: $\left.8.8 \times 10^{7}\right)$ were displayed on phage, cyclized and panned in one selection round against MMP-2. Peptides containing three amino acids in the first ring and six amino acids, containing the fixed Asp-Ala-lle-Trp core plus two random amino acids, in the second ring were most enriched $\left(\mathrm{ACX}_{3} \mathrm{CDAIWX}_{2} \mathrm{CG}\right.$ ) (Figure $2 \mathrm{~b}$ and Figure $\mathrm{S} 2$ ). While the peptide sequences varied substantially in the $\mathrm{N}$-terminal ring, the two randomized amino acids in the C-terminal ring converged to (Gln, Glu, Val, Leu, or Ala)-Gly, wherein a peptide with Glu-Gly was most active (Figures S2 and S3). For the N-terminal ring, we subsequently tested several different bicyclic peptide sequences found in the phage selections with the now optimized sequence of AspAla-lle-Trp-Glu-Gly in the second ring (Figure S3). Peptide M114 containing the sequence ArgTyr-GIn-Arg in the first ring was most active, showing a $K_{\mathrm{i}}$ of $89 \pm 4 \mathrm{nM}$. Inserting the hydroxamate into M114 improved the affinity like for M21 and yielded the inhibitor M114 ${ }^{\text {hy }}$ with a $K_{\mathrm{i}}$ of $7.7 \pm 0.8 \mathrm{nM}$, which was 15 -fold improved compared to the precursor M21 $1^{\text {hy }}$ (Figure $2 \mathrm{~b}$ ).

\section{Substitution of L- to D-amino acids}

In a first step, we performed a D-alanine screen to identify positions in which D-amino acids were tolerated. In D-amino acids, the side chain points in the opposite direction, and side chains in new locations can potentially make new interactions with the target. We synthesized the peptides without hydroxamate to omit a manual step in the automated synthesis and compared the activities to M114. While substitution to D-alanine led to large losses in binding affinity for most amino acid positions, mutating Arg6 and Gly13 to D-Ala conserved the $K_{\mathrm{i}}$ $(<15 \%$ change; Fig. 3a), indicating that these positions tolerated the new side-chain orientation. We subsequently tested diverse D-amino acids in these positions to search for side chains that could form productive interactions with the target. While no improvement could be achieved by mutating Arg6 (data not shown), several D-amino acids in place of Gly13 showed improved activity, including M215 that contained a D-Phe and improved the activity by around 2-fold ( $K_{\mathrm{i}}=49 \pm 3 \mathrm{nM}$; Fig. 3b). Although the Arg6 $\rightarrow$ D-Ala substitution did not improve the activity, Arg residues are common cleavage sites notorious for decreasing proteolytic stability, so we kept the equivalently active D-Ala substitution to reduce the chances of peptide cleavage at the Arg residue. 
Importance of bicyclic format for affinity and selectivity

To study whether the bicyclic ring system was relevant for the high activity and target selectivity, we synthesized the two peptide rings of $\mathrm{M} 219^{\text {hy }}\left(K_{\mathrm{i}}=1.9 \pm 0.5 \mathrm{nM}\right)$ separately and made a linear analogue in which the cysteines were replaced by alanines to prevent disulfide cyclization. The two rings inhibited MMP-2 with $K_{i}$ s of $63,000 \pm 17,000 \mathrm{nM}$ (N-term; 33'000-fold less) and $71 \pm 14 \mathrm{nM}$ (C-term; 37-fold less), respectively, confirming the importance of the Cterminal ring, but showing that the $\mathrm{N}$-terminal ring contributed also substantially to the activity (Figure 4c). The linear peptide bound with a 1,400-fold weaker $K_{\mathrm{i}}(2,700 \pm 300 \mathrm{nM})$, highlighting the importance of the (bi)cyclic configuration of the inhibitor (Figure 4c). When testing against other MMP proteins, the N-terminal ring was contributing slightly less to the affinity of the bicyclic peptide (Figure 4d; see arrows showing affinity contributed by $\mathrm{N}$-term for binding to MMP-2, MMP-3, MMP-12 and MMP-20), indicating that the N-terminal ring, while not contributing as strongly to the activity of the inhibitor, is important for providing selectivity to MMP-2. This could be due to the formation of direct contacts with the target or by indirectly imposing conformational changes in the C-terminal ring that improve the affinity for MMP-2 (Figure 4d and Figure S4).

\section{Stability and degradation pathways of MMP-2 inhibitors}

We further analyzed the degradation pathways of APP-IP and M219 hy by using LC-MS to analyze the metabolites formed upon plasma incubation. APP-IP was rapidly degraded and showed multiple truncation products, indicating several protease-accessible peptide bonds (Figure S5a). Intact M219 hy eluted as one major peak even after eight hours of incubation in plasma (Figure S5b). Analysis of the species in the peak identified two major products, intact M219hy that disappeared with a half-life of $4.8 \pm 0.4$ hours and inhibitor without the hydroxamate group (M219) that formed over time (Figure 5b). After eight hours of incubation in blood plasma, the macrocyclic ring structure of M219hy remained intact, showing the suitability of the bicyclic format as a protease-resistant scaffold for MMP inhibitor development. 


\section{Supplementary Materials and Methods}

\section{Expression and purification of pro-MMP-2}

Human pro-MMP-2 was expressed in transiently transfected human embryonic kidney (HEK) cells as follows. Suspension-adapted HEK-293 cells were grown in one liter of serum-free ExCell 293 medium (SAFC Biosciences) in the presence of $4 \mathrm{mM}$ of glutamine and $3.75 \mathrm{mM}$ of histone deacetylase inhibitor valproic acid in an orbitally shaken five-liter glass bottle at 180 rpm at $37^{\circ} \mathrm{C}$ in the presence of $5 \% \mathrm{CO}_{2}$. Cells at a density of $20 \times 10^{6} \mathrm{cells} / \mathrm{ml}$ were transfected with the vector pcDNA3-MMP-2 (a kind gift from Prof. Dr. Eric Howard, University of Oklahoma, USA) using linear polyethylenimine. After seven days, cells were harvested by centrifugation for $15 \mathrm{~min}$ at $4^{\circ} \mathrm{C}$. Cell debris was removed from the medium by filtration through $0.45 \mu \mathrm{m}$ PES membranes. The recombinant protein was purified from the conditioned medium by size exclusion chromatography on a HiPrep 26/60 Sephacryl S-200 high resolution column (GE Healthcare) using PBS, pH 7.4 as buffer. The purity of the proMMP-2 was greater than $95 \%$ by SDS-PAGE.

\section{Biotinylation of human proMMP-2}

The recombinant pro-MMP-2 $(4.5 \mu \mathrm{M})$ in PBS $(\mathrm{pH} 7.4)$ was incubated with a five-fold excess of EZ-link Sulfo-NHS-LC-Biotin $\left(22.5 \mu \mathrm{M}\right.$, Pierce) for $1 \mathrm{hr}$ at $25^{\circ} \mathrm{C}$. Unreacted biotin was removed by three repetitive cycles of concentration in a Vivaspin-20 filter (MWCO of 10,000, Sartorius-Stedim Biotech $\mathrm{GmbH}$ ) and dilution with TNC buffer (50 mM Tris- $\mathrm{HCl}, \mathrm{pH} 7.5,150$ $\mathrm{mM} \mathrm{NaCl}, 10 \mathrm{mM} \mathrm{CaCl}_{2}$ ). The ability of the biotinylated MMP-2 to bind to either streptavidin or neutravidin was verified by incubating the protein with magnetic streptavidin and neutravidin beads respectively and analyzing the bound and unbound protein fractions by SDS-PAGE.

\section{Activation of human pro-MMP-2}

Purified pro-MMP-2 (1 to $5 \mu \mathrm{M}$ ) in TNC buffer was incubated with $2 \mathrm{mM}$ of freshly prepared 4aminophenylmercuric acetate (APMA) for $1 \mathrm{hr}$ at $37^{\circ} \mathrm{C}$ (APMA stock: $200 \mathrm{mM}$ in $\mathrm{NaOH}$ ). Activated MMP-2 was purified by size exclusion chromatography on a Superdex 75 10/300 GL high-resolution column (GE Healthcare) using TNC buffer. 


\section{Phage display selection of bicyclic peptides}

Bacterial cells of a phage library glycerol stock were added to a $2 \mathrm{~L}$ falcon flask containing 500 $\mathrm{ml}$ of $2 \mathrm{YT} /$ chloramphenicol $\left(30 \mu \mathrm{g} / \mathrm{ml}\right.$ ) medium to obtain an $\mathrm{OD}_{600}$ of 0.1 . The culture was shaken $(200 \mathrm{rpm})$ for $16 \mathrm{hr}$ at $30^{\circ} \mathrm{C}$. Bacterial cells were pelleted by centrifugation at $16,000 \mathrm{~g}$ and $4^{\circ} \mathrm{C}$ for $30 \mathrm{~min}$, and the phage in the supernatant were purified by PEG-precipitation as follows. Briefly, 0.2 volumes of PEG solution ( $20 \%(\mathrm{w} / \mathrm{v})$ polyethylene glycol $6000,2.5 \mathrm{M} \mathrm{NaCl}$ ) was added to the supernatant, mixed, incubated on ice for $30 \mathrm{~min}$, and centrifuged at 2,700 $\mathrm{g}$ and $4^{\circ} \mathrm{C}$ for 30 min. PEG-purified phage, typically $10^{11}-10^{12}$ t.u. (transducing units) were resuspended in $20 \mathrm{ml}$ of $20 \mathrm{mM} \mathrm{NH}_{4} \mathrm{HCO}_{3}, 5 \mathrm{mM}$ EDTA, $\mathrm{pH}$ 8.0. Disulfide bridges were reduced by addition of $1 \mathrm{mM}$ of TCEP and incubation at $42^{\circ} \mathrm{C}$ for $1 \mathrm{hr}$. The concentration of TCEP was subsequently reduced by repetitive concentration and dilution steps with reaction buffer (20 mM NH${ }_{4} \mathrm{HCO}_{3}, 5 \mathrm{mM}$ EDTA, pH 8.0, degassed) in a Vivaspin-20 filter (MWCO of 10,000 , Sartorius-Stedim Biotech $\mathrm{GmbH}$ ). The volume of the phage solution was adjusted to $32 \mathrm{ml}$ with reaction buffer and $8 \mathrm{ml}$ of $50 \mu \mathrm{M}$ tris-(bromomethyl)benzene (TBMB) in acetonitrile $(\mathrm{MeCN})$ were added to obtain a final TBMB concentration of $10 \mu \mathrm{M}$. The reaction was incubated at $30^{\circ} \mathrm{C}$ for $1 \mathrm{hr}$ before non-reacted TBMB was removed by precipitation of the phage with 0.2 volumes of $20 \%(\mathrm{w} / \mathrm{v})$ polyethylene glycol $6000,2.5 \mathrm{M} \mathrm{NaCl}$ on ice and centrifugation at $2,700 \mathrm{~g}$ and $4^{\circ} \mathrm{C}$ for 30 minutes. The phage pellet was resuspended in $3 \mathrm{ml}$ of washing buffer (10 mM Tris-Cl, pH 7.4, $150 \mathrm{mM} \mathrm{NaCl}, 10 \mathrm{mM} \mathrm{MgCl}_{2}, 1 \mathrm{mM} \mathrm{CaCl}_{2}$ ). Biotinylated active MMP$2(180 \mu \mathrm{g})$ was added to $50 \mu \mathrm{l}$ magnetic streptavidin beads (Dynabeads M-280 from Invitrogen Dynal Biotech AS) in washing buffer and incubated on a rotating wheel for $10 \mathrm{~min}$ at room temperature (RT). The magnetic beads were then washed with $0.5 \mathrm{ml}$ washing buffer and incubated for $30 \mathrm{~min}$ at RT with $0.5 \mathrm{ml}$ washing buffer containing $1 \%(\mathrm{w} / \mathrm{v}) \mathrm{BSA}$ and $0.1 \%(\mathrm{v} / \mathrm{v})$ Tween 20. At the same time the chemically modified phage (typically $10^{10}-10^{11} \mathrm{t}$.u. dissolved in $3 \mathrm{ml}$ of washing buffer) were blocked by addition of $1.5 \mathrm{ml}$ of washing buffer containing $3 \%$ $(\mathrm{w} / \mathrm{v}) \mathrm{BSA}$ and $0.3 \%(\mathrm{v} / \mathrm{v})$ Tween 20 for 30 minutes. The blocked beads/target protein mixture $(0.5 \mathrm{ml})$ and phage $(4.5 \mathrm{ml})$ were mixed together and incubated for 30 minutes on a rotating wheel at room temperature. The beads were washed eight times with washing buffer containing $0.1 \%(\mathrm{v} / \mathrm{v})$ Tween 20 and twice with washing buffer. The phage were eluted by incubation with $100 \mu$ of $50 \mathrm{mM}$ glycine, $\mathrm{pH} 2.2$ for 5 minutes (pH-dependent elution), and then transferred to $50 \mu$ of $1 \mathrm{M}$ Tris- $\mathrm{Cl}, \mathrm{pH} 8.0$ for neutralization. The eluted phage were incubated with $30 \mathrm{ml}$ of TG1 cells at $\mathrm{OD}_{600}$ of 0.4 for 90 minutes at $37^{\circ} \mathrm{C}$, and the cells were plated on large 2YT/chloramphenicol (30 $\mathrm{gg} / \mathrm{ml}$ chloramphenicol) plates. The second and third round of panning were performed following the same procedure but using in the second round 
neutravidin-coated magnetic beads instead of streptavidin to prevent the enrichment of streptavidin-specific peptide binders. Neutravidin beads were prepared by reacting $0.8 \mathrm{mg}$ neutravidin (Pierce) with $0.5 \mathrm{ml}$ of tosyl-activated magnetic beads $\left(2 \times 10^{9}\right.$ beads $/ \mathrm{ml}$; Dynabeads M-280, Invitrogen Dynal Biotech AS) according to the supplier's instructions.

\section{Cloning of affinity maturation library}

Seven phage libraries were created by inserting DNA sequences encoding the semi-random peptide sequences Ala-Cys-(Xaa) ${ }_{m}$-Cys-Asp-Ala-Ile-Trp-(Xaa) $)_{n}$-Cys, $m=2-6, n=2$ or $m=4$, $\mathrm{n}=2-4$, amino acids), the linker Gly-Gly-Ser-Gly, and the disulphide-free domains D1 and D2 into the phage vector 21 tet $^{31}$. The insert was step-wise created in two consecutive PCR reactions. First, the genes of D1 and D2 were PCR-amplified with the two primers, prepcr (5'-GGCGGTTCTGGCGCTGAAACTGTTGAAAGTAG-3') and sfi2notfo (5'-CCATGGCCCCCGAGGCCGCGGCCGCATTGACAGG-3'), using the vector fdg3p0ss $21^{32}$ as a template. Second, the DNA encoding the random peptides was appended in a PCR reaction using seven primers of the type 5'CTATGCGGCCCAGCCGGCCATGGCAGCATGC(NNK) mTGCGATGCGATTTGG(NNK) $_{n}$ TGT GGCGGTTCTGGCGCTG-3' ( $m=2-6, n=2$ or $m=4, n=2-4)$ and the primer sfi2notfo. The PCR products were digested with Sfil (underlined in primers) and ligated into Sfil-digested vector 21 tet. For each sub-library, $100 \mu \mathrm{g}$ and $30 \mu \mathrm{g}$ of Sfil-digested vector and PCR product, respectively, were ligated, purified by filtration and electroporated into E. coli TG1 cells. After electroporation, cells were incubated for $1 \mathrm{hr}$ at $37^{\circ} \mathrm{C}$ in $2 \mathrm{YT}$ medium and plated on large (20 $\mathrm{cm}$ diameter) chloramphenicol $(30 \mu \mathrm{g} / \mathrm{ml}) 2 \mathrm{YT}$ plates. Colonies were scraped off the plates with 2YT media, supplemented with $10 \% \mathrm{v} / \mathrm{v}$ glycerol and stored at $-80^{\circ} \mathrm{C}$. The number of transformants from all seven sub-libraries together were $8.8 \times 10^{7}$.

\section{Peptide Synthesis}

Solid-phase peptide synthesis was performed on an Advanced ChemTech $348 \Omega$ peptide synthesizer (AAPPTec) using standard Fmoc procedures. Rink Amide AM resin was used as solid support and DMF as solvent. Peptides were synthesized at a $0.03 \mathrm{mmol}$ scale to obtain around $10-20 \mathrm{mg}$ of pure peptide. Peptide couplings were performed twice for each natural amino acid by reacting amino acid (4 eq., $600 \mu \mathrm{l} 0.2 \mathrm{M}$ in DMF), HBTU/HOBt (4 eq. each, 267 $\mu \mathrm{l} 0.45 \mathrm{M}$ in DMF) and DIPEA (6 eq., $360 \mu \mathrm{l} 0.5 \mathrm{M}$ in DMF) at RT for $30 \mathrm{~min}$ at $400 \mathrm{rpm}$. The coupling of unnatural amino acids (2 eq., $600 \mu \mathrm{l} 0.1 \mathrm{M}$ in DMF) was performed once using 
HATU (2 eq., $650 \mu \mathrm{l} 0.1 \mathrm{M}$ in DMF) and DIPEA (4 eq., $250 \mu \mathrm{l} 0.5 \mathrm{M}$ in DMF). The resin was washed four times with DMF after the coupling reaction. The $\mathrm{N}$-terminal Fmoc protecting group was removed with piperidine ( $20 \% \mathrm{v} / \mathrm{v})$ in DMF (RT, $2 \times 5 \mathrm{~min}, 400 \mathrm{rpm})$. The resin was washed five times with DMF after Fmoc removal. Fmoc-L- $\alpha$-amino acids, HBTU, HOBt and Rink Amide AM resin were purchased from GL Biochem. Non-canonical Fmoc-amino acids were purchased from Bachem, Chem-Impex, PolyPeptide and TCI. Peptides were cleaved from the solid support and protecting groups removed by incubation in $5 \mathrm{ml}$ cleavage cocktail $(90 \%$ TFA, 2.5\% ethane-1,2-dithiol, $2.5 \%$ phenol, $2.5 \%$ thioanisole, $2.5 \% \mathrm{H}_{2} \mathrm{O}$ ) for $2 \mathrm{hrs}$ with shaking. The resin was removed by vacuum filtration, and the peptides were precipitated with ice-cold diethyl ether $(50 \mathrm{ml})$, incubated for $30 \mathrm{~min}$ at $-20^{\circ} \mathrm{C}$, and pelleted by centrifugation $(2,700 \mathrm{~g}, 5$ $\min )$. The diethyl ether was discarded, the precipitate washed twice with diethyl ether and the remaining solvent evaporated at room temperature.

\section{Hydroxamate modification}

The hydroxamate group was introduced into the peptides on solid phase as described in the following. Peptides were synthesized using rink amide resin $(0.03 \mathrm{mmol}$ scale $)$ and Fmoc chemistry as described above. In the position of the hydroxamate-modified amino acid, an aspartic acid side-chain protected with 2-phenylisopropyl ester was introduced using FmocAsp(2-phenylisopropyl ester)-OH as a building block (Bachem). The 2-phenylisopropyl ester protecting group was selectively removed by the addition of $5 \mathrm{ml}$ TFA $(2 \%(\mathrm{v} / \mathrm{v}))$ in dichloromethane and shaking for $2 \mathrm{~min}$ at room temperature. The reagents were removed by filtration and the procedure repeated five times. The beads were washed five times with DMF. The carboxylic acid of the aspartate was subsequently modified with hydroxamic acid as follows. $\mathrm{NH}_{2} \mathrm{OH} \bullet \mathrm{HCl}$ (2 eq., $0.5 \mathrm{ml}$ ) in DMF was premixed with $\mathrm{KOH}$ (2 eq., $0.5 \mathrm{ml}$ ) in DMF and added to the peptide on resin. pyBOP in DMF (1.2 eq., $1 \mathrm{ml}$ ) and DIPEA in DMF (6 eq., $1 \mathrm{ml}$ ) were added and the reaction incubated under shaking (400 rpm) for $5 \mathrm{~min}$ at room temperature. The reagents were removed, the reaction repeated once, the peptides washed four times with DMF and the peptides cleaved from the solid support as described above.

\section{Peptide cyclization and purification}

Crude peptide at a concentration of $1 \mathrm{mM}$ was reacted with $1.4 \mathrm{mM}$ of TBMB in $70 \% \mathrm{NH}_{4} \mathrm{HCO}_{3}$ buffer (60 mM, pH 8.0) and $30 \% \mathrm{MeCN}$ for $1 \mathrm{hr}$ at $30^{\circ} \mathrm{C}$. Peptide and TBMB were prepared and mixed using the following solvents, concentrations and volumes exemplified for the 
cyclization of around $50 \mathrm{mg}$ of crude peptide. Six $\mathrm{ml} 4.2 \mathrm{mM}$ peptide in $\mathrm{MeCN} / \mathrm{H}_{2} \mathrm{O}$ (1:2) were mixed with $3.5 \mathrm{ml} 10 \mathrm{mM}$ TBMB in MeCN. Two $\mathrm{ml}$ MeCN were further added and the reaction started by addition of $14 \mathrm{ml}$ of $\mathrm{NH}_{4} \mathrm{HCO}_{3}$ buffer $(60 \mathrm{mM}, \mathrm{pH} 8.0)$. The reaction products were lyophilized, dissolved in $10 \mathrm{ml} \mathrm{H} \mathrm{H}_{2} \mathrm{O}$ containing 10\% (v/v) DMSO, 10\% (v/v) MeCN, and 0.1\% (v/) TFA and purified by reversed-phase HPLC (Waters Prep LC 4000 system) using a preparative C18 RP column (Vydac C18 TP1022 column, $250 \times 22 \mathrm{~mm}, 10 \mu \mathrm{m}, 300 \AA$ ) and a linear gradient of $50 \%$ solvent $B\left(\mathrm{MeCN}, 0.1 \%[\mathrm{v} / \mathrm{v}]\right.$ TFA) in solvent $\mathrm{A}\left(\mathrm{H}_{2} \mathrm{O}, 0.1 \%[\mathrm{v} / \mathrm{v}] \mathrm{TFA}\right)$ in $25 \mathrm{~min}$ at a flow of $20 \mathrm{ml} / \mathrm{min}$. Absorbance was detected at $220 \mathrm{~nm}$. Fractions containing the desired peptide were lyophilized, weighed, and dissolved by the sequential addition of DMSO and $\mathrm{H}_{2} \mathrm{O}$ to reach a final concentration of $2 \mathrm{mM}$ of peptide in $\mathrm{H}_{2} \mathrm{O}$ containing $3 \%(\mathrm{v} / \mathrm{v})$ DMSO. The concentrations of the peptides were confirmed by measuring the absorption at $280 \mathrm{~nm}$.

\section{HPLC and mass spectrometric analysis}

The molecular mass of the purified peptides was determined on a single quadrupole mass spectrometer in positive ion mode using electrospray ionization of a LC-MS device (LCMS2020, Shimadzu). The purity of the peptides was determined by analytical RP-HPLC (Agilent 1260 HPLC system) using an analytical C18 column (Agilent Zorbax 300SB-C18, $4.6 \mathrm{~mm} \times$ $250 \mathrm{~mm}, 5 \mu \mathrm{m})$ and a linear gradient of $0-50 \%$ solvent $B(\mathrm{MeCN}, 0.1 \%[\mathrm{v} / \mathrm{v}] \mathrm{TFA})$ in solvent $A$ $\left(\mathrm{H}_{2} \mathrm{O}, 5 \%[\mathrm{v} / \mathrm{v}] \mathrm{MeCN}, 0.1 \%[\mathrm{v} / \mathrm{v}] \mathrm{TFA}\right)$ in $15 \mathrm{~min}$ at a flow of $1 \mathrm{ml} / \mathrm{min}$. Absorbance was measured at $220 \mathrm{~nm}$.

\section{MMP inhibition assays}

The inhibitory activity of bicyclic peptides was determined by measuring residual protease activity with a fluorogenic substrate. All assays were performed in assay buffer containing 50 $\mathrm{mM}$ Tris- $\mathrm{Cl}, \mathrm{pH} 7.5,150 \mathrm{mM} \mathrm{NaCl}, 10 \mathrm{mM} \mathrm{CaCl}_{2}$ and $0.1 \% \mathrm{w} / \mathrm{v} \mathrm{BSA}$, in a volume of $150 \mu \mathrm{l}$. For all MMPs except for MMP-19, activity was measured with the FRET substrate Mca-LysPro-Leu-Gly-Leu-Dap(DnP)-Ala-Arg-NH2 (FS-6, GL Biochem). For MMP-19, the substrate TQ3-GABA-Pro-Cha-Abu-Smc-His-Ala-Dab(6'-TAMRA)-Ala-Lys- $\mathrm{NH}_{2}$ (OMNIMMP® RED,

Enzo life sciences) was applied. The enzymes and substrates were used at the following concentrations: $10 \mathrm{mU} / \mu \mathrm{l}$ of MMP-1 (Enzo life sciences kit, cat \# BML-AK308-0001) and 20 $\mu \mathrm{M}$ of substrate; $0.5 \mathrm{nM}$ of MMP-2 (expressed in house) and $10 \mu \mathrm{M}$ of substrate; $7.5 \mathrm{mU} / \mu \mathrm{l}$ of MMP-3 (Enzo life sciences kit) and $20 \mu \mathrm{M}$ of substrate; $0.25 \mathrm{mU} / \mu \mathrm{l}$ of MMP-7 (Enzo life sciences kit) and $20 \mu \mathrm{M}$ of substrate; $3 \mathrm{mU} / \mu \mathrm{l}$ of MMP-8 (Enzo life sciences kit) and $20 \mu \mathrm{M}$ of 
substrate; $4 \mathrm{mU} / \mu$ l of MMP-9 (Enzo life sciences kit) and $10 \mu \mathrm{M}$ of substrate; $3 \mathrm{mU} / \mu \mathrm{l}$ of MMP10 (Enzo life sciences, cat \# BML-SE329-0010) and $20 \mu \mathrm{M}$ of substrate; $2.5 \mathrm{mU} / \mu \mathrm{l}$ of MMP-12 (Enzo life sciences kit) and $10 \mu \mathrm{M}$ of substrate; $0.1875 \mathrm{mU} / \mu \mathrm{l}$ of MMP-13 (Enzo life sciences kit) and $5 \mu \mathrm{M}$ of substrate; $2.5 \mathrm{mU} / \mu \mathrm{l}$ of MMP-14 (Enzo life sciences kit) and $10 \mu \mathrm{M}$ of substrate; $0.75 \mathrm{mU} / \mu \mathrm{l}$ of MMP-19 (Enzo life sciences kit) and $0.75 \mu \mathrm{M}$ of substrate, $7.5 \mathrm{mU} / \mu \mathrm{l}$ of MMP20 (Enzo life sciences, cat \# BML-SE540-0010) and $5 \mu \mathrm{M}$ of substrate. The reaction was pipetted by adding $50 \mu$ of bicyclic peptide in assay buffer to $50 \mu$ of enzyme in assay buffer and incubating for 15 minutes at $37^{\circ} \mathrm{C}$ before $50 \mu \mathrm{l}$ of $1.5-60 \mu \mathrm{M}$ of fluorogenic substrate in assay buffer was added to measure the residual protease activity with an Infinite M200Pro fluorescence plate reader (Tecan) for a period of $30 \mathrm{~min}$ at $37^{\circ} \mathrm{C}$ with a read every minute. For the FS-6 substrate, excitation was measured at $325 \mathrm{~nm}$ and emission at $400 \mathrm{~nm}$. For the OMNIMMP® RED substrate, excitation was measured at $545 \mathrm{~nm}$ and emission at $576 \mathrm{~nm}$. The bicyclic peptides were serially diluted from the $1 \mathrm{mM}$ stock solutions two-fold using assay buffer. The $I C_{50}$ values were determined by fitting sigmoidal curves to the data using the following four-parameter logistic equation used for dose response curves wherein $x$ is the peptide concentration, $\mathrm{y}$ is the percent residual protease activity, $\mathrm{p}$ is the Hill slope, and IC50 is the peptide concentration at which $50 \%$ of the enzymatic activity is inhibited.

$$
y=\frac{100}{1+10^{(\log I C 50-x) p}}
$$

The inhibition constants $\left(K_{\mathrm{i}}\right)$ were calculated according to the equation of Cheng and Prusoff $K_{\mathrm{i}}=I C_{50} /\left(1+\left([\mathrm{S}]_{0} / K_{\mathrm{m}}\right)\right.$ wherein $I C_{50}$ is the peptide concentration at which $50 \%$ of the enzymatic activity is inhibited, $[\mathrm{S}]_{0}$ is the total substrate concentration, and $K_{\mathrm{M}}$ is the Michaelis-Menten constant. $K_{M}$ values for the following MMPs were determined: MMP-2: $30 \pm 2 \mu \mathrm{M}$, MMP-3: 90 $\pm 7 \mu \mathrm{M}$, MMP-7: $42 \pm 5 \mu \mathrm{M}$, MMP-8: $58 \pm 1 \mu \mathrm{M}$ MMP-9: $30 \pm 2 \mu \mathrm{M}, \mathrm{MMP}-10: 73 \pm 13 \mathrm{x} \mu \mathrm{M}$, MMP-12: $58 \pm 1 \mu \mathrm{M}$, MMP-13: $7.4 \pm 0.4 \mu \mathrm{M}$ MMP-14: $10.1 \pm 0.1 \mu \mathrm{M}, \mathrm{MMP}-20: 37 \pm 4 \mu \mathrm{M}$. These values were in accordance with previously reported values for the applied substrates. $K_{\mathrm{M}}$ values for the following MMPs were taken from literature: MMP-1: $27.5 \mu \mathrm{M}, \mathrm{MMP}-19: 14$ $\mu \mathrm{M}$. 
Inhibition of MMP-2 auto-proteolysis

MMP-2 (100 nM) in TNC buffer was incubated with and without $0.1,0.5$, and $1 \mu \mathrm{M}$ of M114hy for $1 \mathrm{hr}$ at $37^{\circ} \mathrm{C}$, and $20 \mu \mathrm{l}$ of the reaction was analyzed by SDS-PAGE using a $10 \%$ acrylamide gel (CBS Scientific), Tris-Tricine ClearPAGE SDS running buffer, and silver staining (Pierce Silver Stain Kit).

\section{Plasma stability determined by measuring residual inhibitory activity}

A volume of $100 \mu \mathrm{l}$ of bicyclic peptide $\left(1 \mathrm{mM}\right.$ in $\mathrm{H}_{2} \mathrm{O}$ ) was added to $900 \mu \mathrm{l}$ of human plasma (Innovative Research) to obtain a final inhibitor concentration of $100 \mu \mathrm{M}$. The mixture was incubated in a water bath at $37^{\circ} \mathrm{C}$. At different time points, samples of $30 \mu \mathrm{l}$ were removed, diluted to $200 \mu$ with aqueous buffer (50 mM Tris- $\mathrm{HCl}, \mathrm{pH} 7.4,150 \mathrm{mM} \mathrm{NaCl}, 10 \mathrm{mM} \mathrm{CaCl}$ ), and incubated for $20 \mathrm{~min}$ at $65^{\circ} \mathrm{C}$ to inactivate plasma proteases. The peptide/plasma samples were stored at $-20^{\circ} \mathrm{C}$ until the residual inhibitory activity of the peptides was measured in a MMP-2 inhibition assay. For the activity assay, the peptide/plasma samples were centrifuged for $5 \mathrm{~min}$ at $16,000 \mathrm{~g}$, and serial two-fold dilutions of the supernatant were prepared. The residual activity of $0.5 \mathrm{nM}$ of MMP-2 was measured using $10 \mu \mathrm{M}$ of the Mca-Lys-Pro-Leu-GlyLeu-Dap(DnP)-Ala-Arg- $\mathrm{NH}_{2}$ substrate. The $I C_{50}$ values were determined by fitting sigmoidal curves to the data using the four-parameter logistic equation used for dose response curves indicated above. Residual inhibition in \% was calculated using the equation $I C_{50}, 0 \mathrm{~h} /$ $I C_{50}, \mathrm{xh}^{*} 100$ wherein $I C_{50}, 0 \mathrm{~h}$ is the functional strength of the inhibitor at time point 0 and $I C_{50}, \mathrm{xh}$ is the functional strength of inhibitor after one of the different plasma incubation periods mentioned above.

\section{Plasma stability determined by HPLC analysis}

A volume of $80 \mu \mathrm{l}$ of bicyclic peptide $\left(1 \mathrm{mM}\right.$ in $\mathrm{H}_{2} \mathrm{O}$ ) was added to $720 \mu$ l of mouse plasma (Innovative Research) to obtain a final inhibitor concentration of $100 \mu \mathrm{M}$ and was incubated at $37^{\circ} \mathrm{C}$ in a water bath. Samples of $90 \mu \mathrm{l}$ were collected at different time points and mixed with $60 \mu \mathrm{l}$ of $6 \mathrm{M}$ guanidinium hydrochloride. The samples were stored at $-20^{\circ} \mathrm{C}$. After collection at all time points, the samples were centrifuged $\left(11,000 \mathrm{~g}, 5 \mathrm{~min}, 4^{\circ} \mathrm{C}\right)$ prior to analysis. The stability and degradation of the peptides was analyzed by analytical RP-HPLC (Agilent 1260 HPLC system) using an analytical C8 column (Waters, Xbridge C8, $4.6 \mathrm{~mm} \times 250 \mathrm{~mm}, 5 \mu \mathrm{m}$, $130 \AA)$ and a linear gradient of $15-65 \%$ solvent $B\left(M e C N, 0.1 \%(v / v)\right.$ TFA) in solvent $A\left(\mathrm{H}_{2} \mathrm{O}\right.$, 
$5 \%[\mathrm{v} / \mathrm{v}] \mathrm{MeCN}, 0.1 \%$ [v/v] TFA) in $30 \mathrm{~min}$ at a flow of $1 \mathrm{ml} / \mathrm{min}$. Absorbance was detected at $220 \mathrm{~nm}$. Peaks corresponding to intact peptide or degradation products were identified by mass spectrometry analysis of the collected fractions using an LCMS-2020 system (Shimadzu). 


\section{Supplementary Tables}

Supplementary Table 1 Selectivity of the bicyclic peptides for MMP-2 over MMP-9. $K_{\mathrm{i}}$ values were determined in triplicate. Mean values and standard deviations (SDs) are indicated.

\begin{tabular}{|c|c|c|}
\hline & \multicolumn{2}{|c|}{$K_{\mathrm{i}}(\mathrm{nM})$} \\
\hline & MMP-2 & MMP-9 \\
\hline M21 & $3,400 \pm 200$ & $>100,000$ \\
\hline M21 hy & $116 \pm 8$ & $54,000 \pm 200$ \\
\hline M114 & $89 \pm 4$ & $64,000 \pm 200$ \\
\hline M114 & $7.7 \pm 0.8$ & $9,500 \pm 130$ \\
\hline
\end{tabular}


Supplementary Table 2 Amino acid conservation in catalytic domain of MMPs. A BLAST search was performed on UniProt using the catalytic domain of MMP-2 with the fibronectin domain removed as a template. The BLOSUM62 alignment score matrix was used for the comparison. For MMP-9, the catalytic domain with the fibronectin domain removed was compared in a pairwise alignment with the catalytic domain of MMP-2. MMPs that were included in the specificity profiling are indicated with an asterisk.

\begin{tabular}{|c|c|c|c|}
\hline Enzyme & $\%$ Identity & \% Similarity & BLOSUM62 Score \\
\hline MMP-13* & 65 & 76 & 592 \\
\hline MMP-9* & 64 & 77 & 557 \\
\hline MMP-3* & 58 & 70 & 521 \\
\hline MMP-20* & 58 & 67 & 517 \\
\hline MMP-12* & 59 & 71 & 506 \\
\hline MMP-10* & 56 & 68 & 493 \\
\hline MMP-1* & 56 & 72 & 486 \\
\hline MMP-8* & 55 & 68 & 482 \\
\hline MMP-7* & 53 & 64 & 469 \\
\hline MMP-24 & 54 & 64 & 441 \\
\hline MMP-11 & 52 & 65 & 430 \\
\hline MMP-27 & 54 & 64 & 427 \\
\hline MMP-26 & 48 & 67 & 425 \\
\hline MMP-14* & 49 & 63 & 425 \\
\hline MMP-16 & 54 & 64 & 424 \\
\hline MMP-15 & 48 & 62 & 405 \\
\hline MMP-25 & 44 & 56 & 348 \\
\hline MMP-19* & 46 & 58 & 327 \\
\hline MMP-17 & 40 & 43 & 321 \\
\hline MMP-28 & 44 & 57 & 320 \\
\hline MMP-23 & 39 & 50 & 278 \\
\hline MMP-21 & 38 & 49 & 230 \\
\hline
\end{tabular}


Supplementary Table 3 Specificity of M219 hy, its $\mathrm{N}$ - or-C-terminal monocyclic rings, and the linear precursor. The activity of the indicated MMPs was measured using fluorogenic substrates in the presence of two-fold peptide dilutions, wherein the highest peptide concentration was $50 \mu \mathrm{M}$. For proteases that were inhibited less than $10 \%$ at $50 \mu \mathrm{M}$, the $K_{\mathrm{i}}$ is indicated as $>\mathrm{IC}_{50} /\left(1+[\mathrm{s}] / \mathrm{K}_{\mathrm{M}}\right)$. For proteases that were inhibited more than $10 \%$ at $50 \mu \mathrm{M}$, the $K_{\mathrm{i}}$ was calculated by fitting the data to a sigmoidal curve.

\begin{tabular}{|c|c|c|c|c|}
\hline & \multicolumn{4}{|c|}{$K_{\text {i }}(\mathrm{nM})$} \\
\hline & M219hy & M219 ${ }^{\text {hy }}$ N-term & M219 ${ }^{\text {hy }}$ C-term & M219hy linear \\
\hline MMP-1 & $>28,900$ & $>28,900$ & $>28,900$ & $>28,900$ \\
\hline MMP-2 & $1.9 \pm 0.5$ & $63,000 \pm 17,000$ & $71 \pm 14$ & $2,700 \pm 300$ \\
\hline MMP-3 & $4.1 \pm 1.1$ & $>40,900$ & $100 \pm 6$ & $38,000 \pm 5,000$ \\
\hline MMP-7 & $7,200 \pm 200$ & $>33,700$ & $50,000 \pm 3,000$ & $>33,700$ \\
\hline MMP-8 & $130,000 \pm 70,000$ & $>37,200$ & $280,000 \pm 90,000$ & $>37,200$ \\
\hline MMP-9 & $40,000 \pm 20,000$ & $>37,500$ & $113,000 \pm 18,000$ & $>37,500$ \\
\hline MMP-10 & $3,100 \pm 300$ & $>39,200$ & $34,700 \pm 300$ & $>39,200$ \\
\hline MMP-12 & $600 \pm 100$ & $>42,700$ & $6800 \pm 1,000$ & $104,000 \pm 15,000$ \\
\hline MMP-13 & $67,000 \pm 9,000$ & $65,000 \pm 3,000$ & $67,000 \pm 10,000$ & $>29,800$ \\
\hline MMP-14 & $11,000 \pm 1600$ & $>25,100$ & $53,000 \pm 6000$ & $>25,100$ \\
\hline MMP-19 & $>47,500$ & $>47,500$ & $>47,500$ & $>47,500$ \\
\hline MMP-20 & $410 \pm 50$ & $>44,100$ & $3,300 \pm 300$ & $55,000 \pm 4,000$ \\
\hline
\end{tabular}




\section{Supplementary Figures}

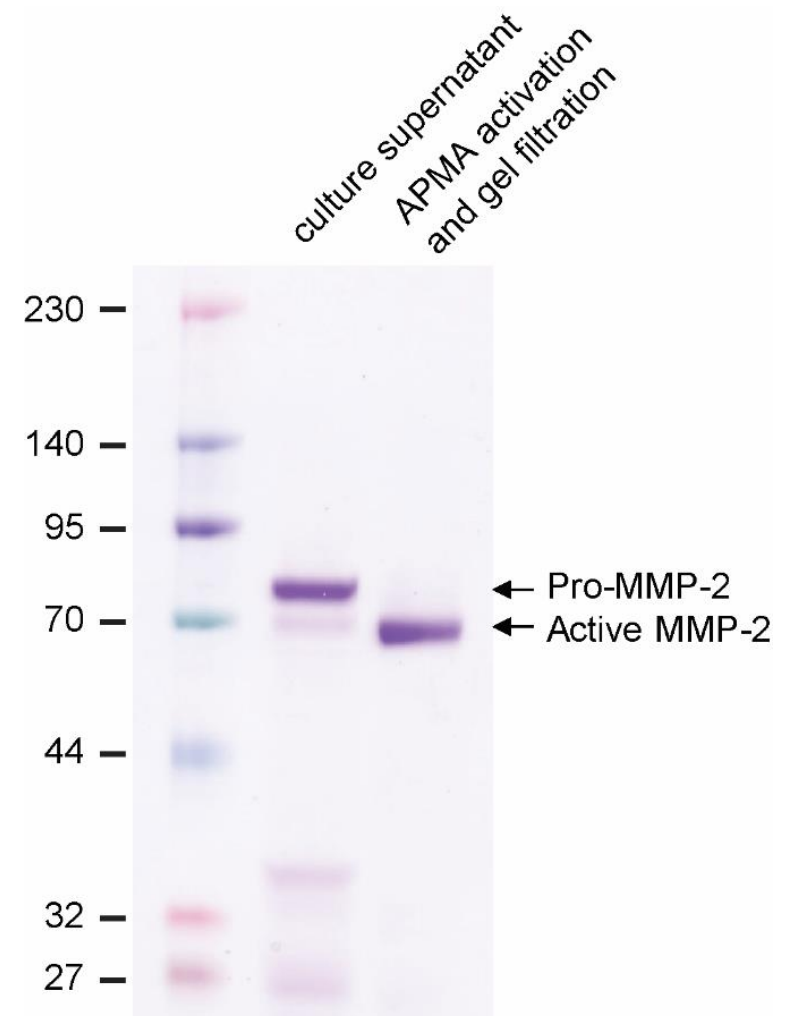

Supplementary Figure 1 Expression, activation, and purification of MMP-2. The protease was expressed as a zymogen in HEK cells. Protein secreted into the culture supernatant was analyzed by SDS-PAGE before and after APMA-activation and purification. 
ACQMCDA I WEGCG $A C$ I M CDA I WF GCG ACG T CDA I WVGCG ACDS CDA I WV Y CG ACQ A C D A I WVVVG ACYRCDA I WLKCG ACV LCDA I WLQCG $A C R Q C D A$ I WAECG ACL LCDA I WQECG ACQRCDA I WKM CG ACM VIDA I WS V C G

$3 \times 6$

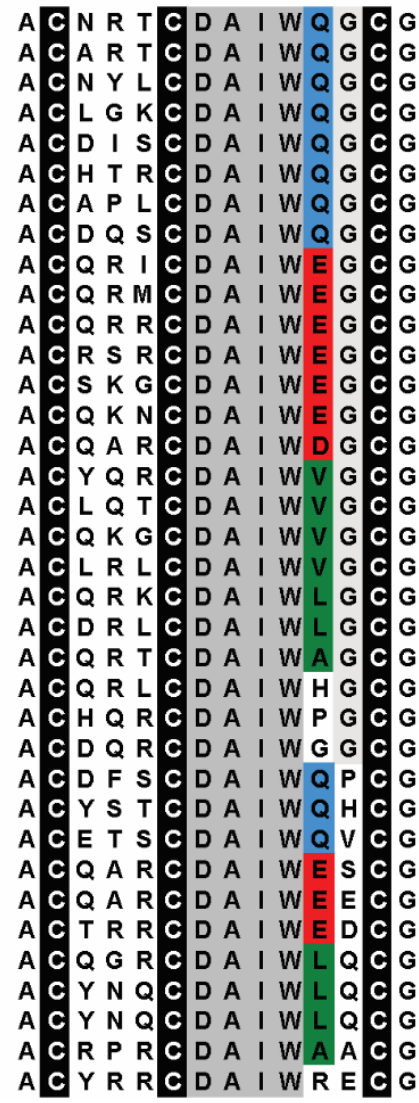

$4 \times 6$

ACQE LWCDA I WLVCG A CQRLKCDA I WV DCG ACQGVGCDA I WVM CG A CA Q A K C D A I WV T C G A CM Q F S CDA I WL I CG ACGFYGCDA I WVGCG A CGWWS CDA I WV QCG ACQLLGCDA I WAECG ACQLLGCDA I WAECG A CQG YWCDA I WA I CG A CS RRE CDA I WA GCG ACRQERCDA I WAGCG A CRY V R CDA I WQGCG A CR Y QR CDA I WG GCG ACV R G A CDA I WG M C G

$5 \times 6$

ACQQFWKCDA I WEGCG A CWRTEGCDA I WD I CG ACARQGNCDAIWQRCG ACMELRRCDA I WG QCG

$6 \times 6$

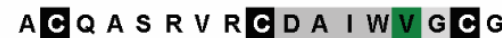
$A C Q Y P Y Y A C D A$ I WV G C G $A C Q V A Q L P C D A$ I WV G C G A CR F S Q G K C D A I WV G C G A C P T N S Q L C D A I WV G C G A C G Q L T R Y C D A I WV G C G A C V A S M L T C D A I WV G C G A CS A Q F F R C D I WV E C G A C Y F S A W P C D A I WV N C G A C S V P Y Q A C D A I WV L C G A C S V P Y Q A C D A I WV L C G A C V A E Q P R C D A I WL L C G ACR A P V R F C D A I WE G C G A C H P Q G T C D A I W F I C G A CWQNA L Q C D A I WR V C G

ACGQDNCDA I WR V R C ACR Q Q R C D A I WG I N C G $A$ C $Q$ E S C D A I WL L G C G A C R Q A R C D A I W T L A C G ACP Q A R C D A I WG A R C G

$4 \times 8$

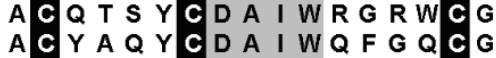

Supplementary Figure 2 The peptides isolated from phage display libraries shown in Figure 2b. The four constant amino acids in the libraries are highlighted in dark grey. Amino acids enriched in the C-terminal ring are highlighted in color. 


\begin{tabular}{|c|c|c|c|c|c|c|c|c|c|c|c|c|c|c|c|c|}
\hline & & & & & & & & & & & & & & & & $K_{\mathrm{i}}(\mu \mathrm{M}):$ \\
\hline M101 & & A & C & $\mathbf{Q}$ & A & $\mathbf{R}$ & C & D & A & I & w & E & $\mathbf{G}$ & C & G & 0.45 \\
\hline M102 & & A & C & $\mathbf{Q}$ & A & $\mathbf{R}$ & C & D & A & I & w & $\mathbf{L}$ & G & C & G & 5.4 \\
\hline M103 & & A & C & $\mathbf{Q}$ & A & $\mathbf{R}$ & C & D & A & I & w & $\mathbf{v}$ & $\mathbf{G}$ & C & G & 5.4 \\
\hline M104 & & A & C & $\mathbf{Q}$ & A & $\mathbf{R}$ & C & D & A & I & w & A & G & C & G & 0.6 \\
\hline M105 & & A & C & $\mathbf{Q}$ & A & $\mathbf{R}$ & C & D & A & I & w & $\mathbf{Q}$ & $\mathbf{G}$ & C & G & 0.51 \\
\hline M106 & & & A & C & $\mathbf{Q}$ & $\mathbf{R}$ & C & D & A & I & W & E & G & C & G & 1.05 \\
\hline M107 & & A & C & $\mathbf{Y}$ & $\mathbf{Q}$ & $\mathbf{R}$ & C & D & A & I & w & $\mathbf{E}$ & G & C & G & 0.21 \\
\hline M108 & & A & C & $\mathbf{Y}$ & $\mathbf{R}$ & $\mathbf{R}$ & C & D & A & I & w & E & G & C & G & 0.27 \\
\hline M109 & & A & C & $\mathbf{Q}$ & $\mathbf{R}$ & $\mathbf{I}$ & C & D & A & I & $\mathbf{w}$ & 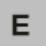 & G & C & G & 0.9 \\
\hline M110 & & A & C & $\mathbf{Q}$ & $\mathbf{R}$ & $\mathbf{R}$ & C & D & A & I & $\mathbf{w}$ & $\mathbf{E}$ & G & C & G & 1.5 \\
\hline M111 & & A & C & $\mathbf{Q}$ & $\mathbf{R}$ & $\mathbf{M}$ & C & D & A & I & $\mathbf{w}$ & $\mathbf{E}$ & G & C & G & 1.2 \\
\hline M112 & & A & C & $\mathbf{R}$ & $\mathbf{s}$ & $\mathbf{R}$ & C & D & A & I & w & E & $\mathbf{G}$ & C & G & 0.9 \\
\hline M113 & A & C & $\mathbf{Q}$ & $\mathbf{R}$ & $\mathbf{L}$ & $\mathbf{K}$ & C & D & A & I & $\mathbf{w}$ & $\mathbf{E}$ & G & C & G & 0.24 \\
\hline M114 & A & C & $\mathbf{R}$ & $\mathbf{Y}$ & $\mathbf{Q}$ & $\mathbf{R}$ & C & D & A & I & w & $\mathbf{E}$ & $\mathbf{G}$ & C & G & $0.089 \pm 0.004$ \\
\hline M115 & A & C & $\mathbf{R}$ & $\mathbf{Q}$ & $\mathbf{A}$ & $\mathbf{R}$ & C & D & A & I & w & E & G & C & G & 0.48 \\
\hline
\end{tabular}

Supplementary Figure 3 Affinity maturation of M21. The indicated peptides were synthesized without the hydroxamate group, purified, and the $K_{\mathrm{i}}$ was determined based on one measurement. The $K_{\mathrm{i}}$ of the best inhibitor, M114, was determined in triplicate. The mean value and SD are indicated. 


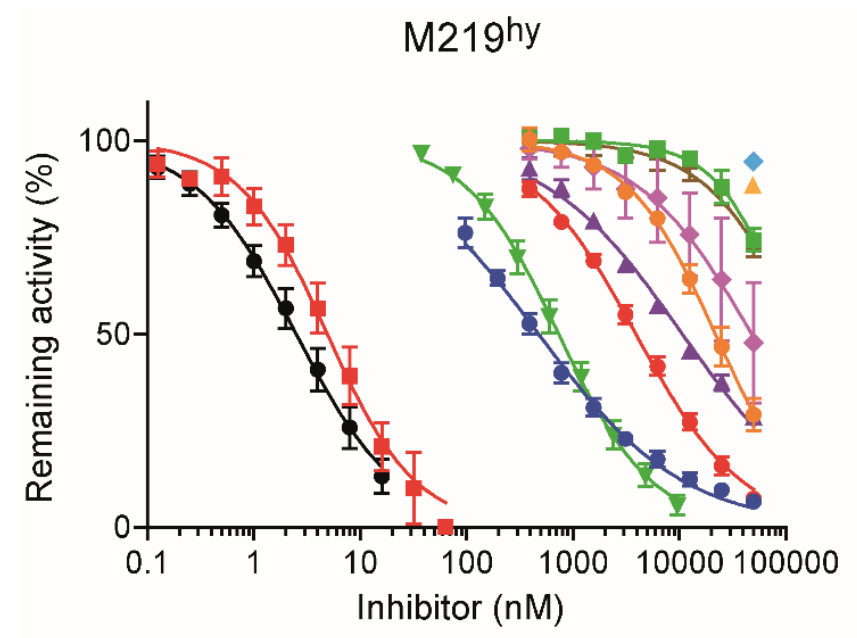

- MMP-1

- MMP-2

- MMP-3

- MMP-7

+ MMP-8

- MMP-9

- MMP-10

v MMP-12

- MMP-13

- MMP-14

- MMP-19

- MMP-20

M219hy N-terminal

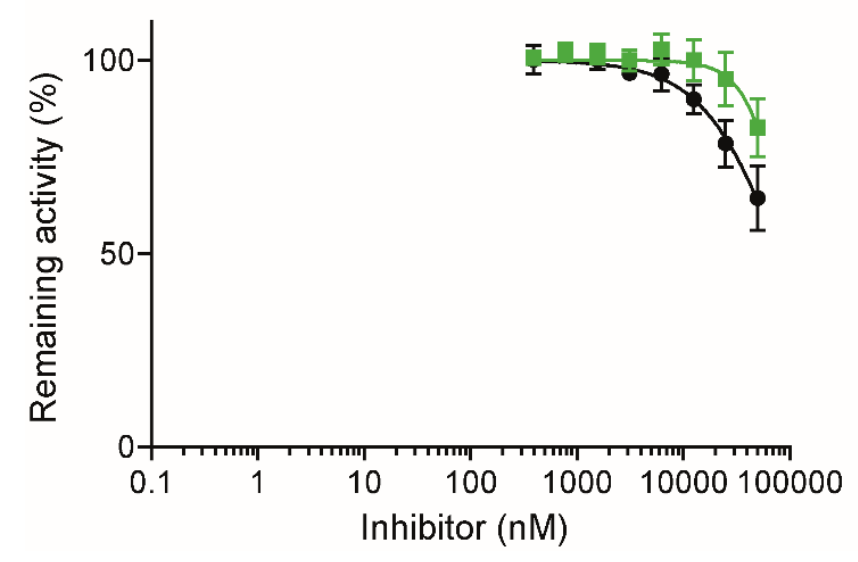

- MMP-2

- MMP-13

Supplementary Figure 4 Specificity of M219hy, its N- and C-terminal rings, and the linear peptide analogue as shown in Figure 4c. Mean values and SD of at least three measurements are indicated. For proteases that were inhibited less than $10 \%$ at $50 \mu \mathrm{M}$, dose response curves were not determined. 


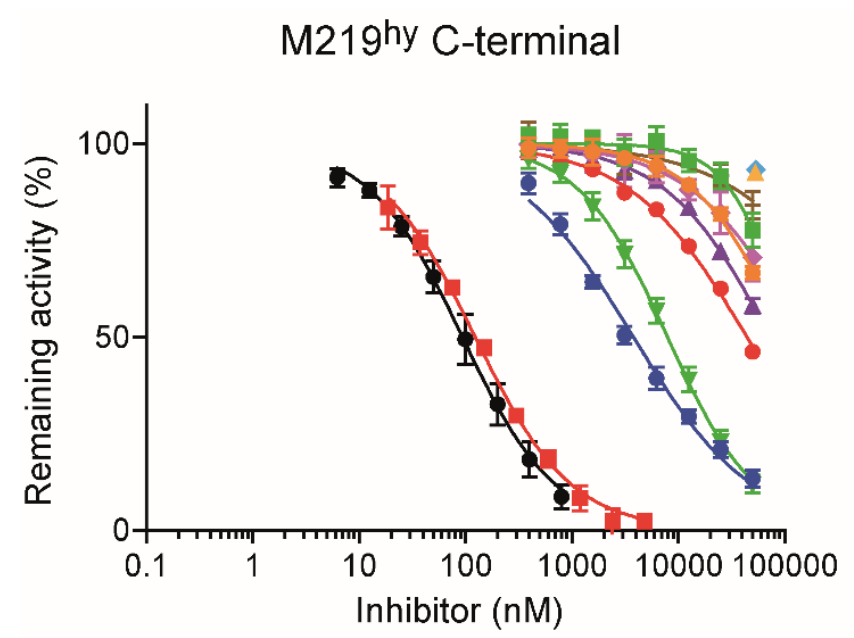

- MMP-1

- MMP-2

- MMP-3

- MMP-7

+ MMP-8

- MMP-9

- MMP-10

$\checkmark \quad M M P-12$

- MMP-13

- MMP-14

$\triangle \quad$ MMP-19

- MMP-20

M219hy linear

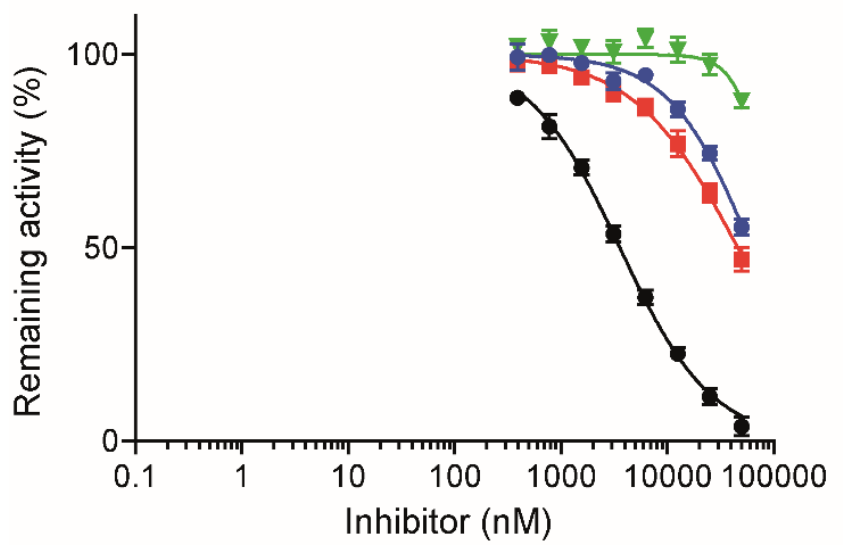

- MMP-2

- MMP-3

$\checkmark \quad M M P-12$

- MMP-20

Supplementary Figure 4 Continued 
a
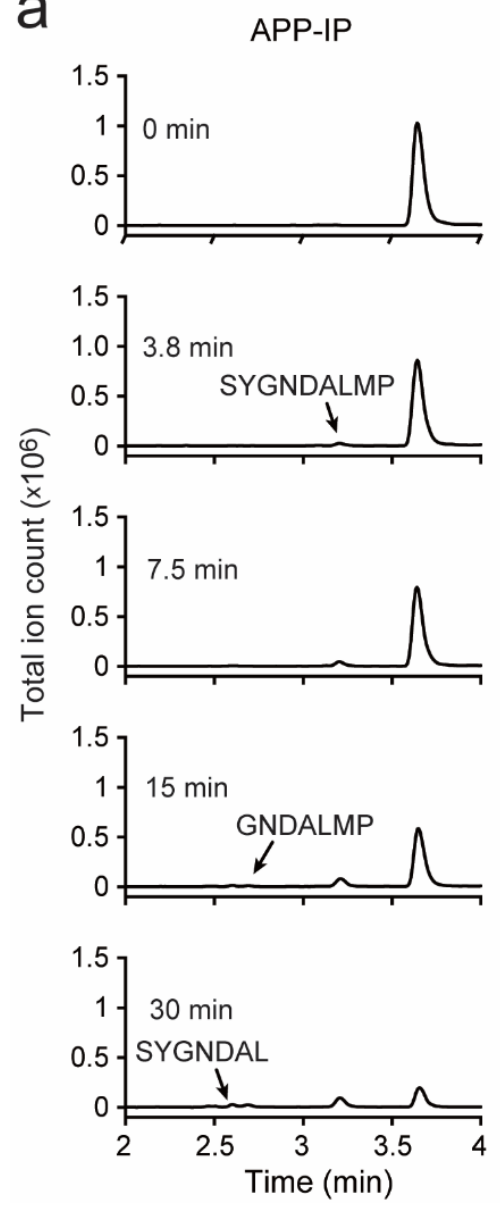

b
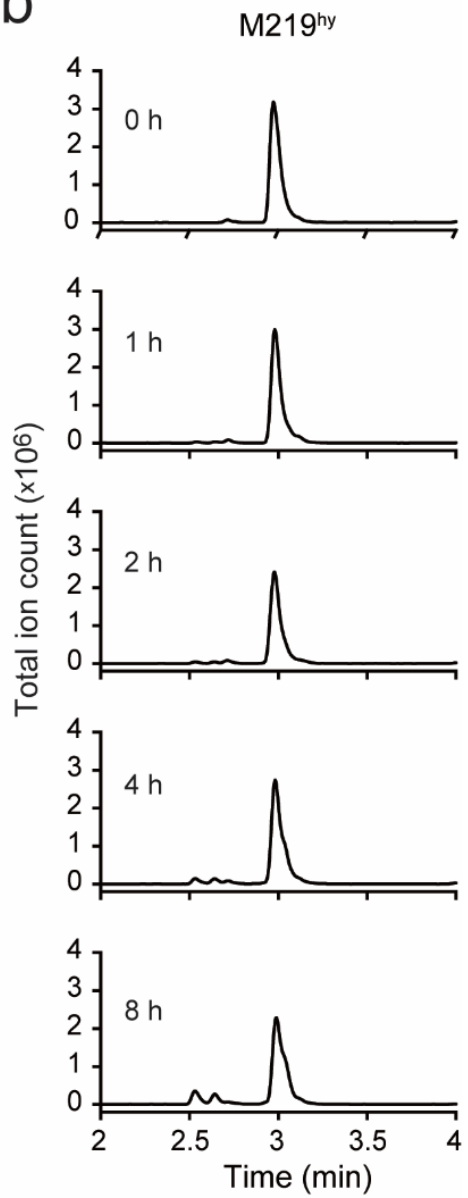

Supplementary Figure 5 Stability of a) APP-IP and b) M219 hy in human plasma. Inhibitors were incubated in human plasma at $37^{\circ} \mathrm{C}$ for the indicated time periods and were analyzed by LC-MS. Total ion count (TIC) at the different elution times is shown. 